Vol. 3, No. 2, June 2021 e-ISSN: 2656-4882 p-ISSN: 2656-5935

http://journal-isi.org/index.php/isi

Published By DRPM-UBD

\title{
Implementasi Perencanaan Strategis SI/TI Pada PT. Prima Teknologi
}

\author{
Rahmad Firdaus ${ }^{1}$, Januar Al Amien ${ }^{2}$ \\ 1,2 Program Studi Teknik Informatika, Universitas Muhammadiyah Riau, Pekanbaru, Indonesia \\ Email:1Rahmadfirdaus@umri.ac.id, 2januaralamien@umri.ac.id
}

\begin{abstract}
The use of IS / IT in a company is one of the keys to success in achieving the company's vision, mission and goals. PT. Prima Teknologi is a company that has not fully implemented the use of IS / IT to help its business operations, namely in terms of business project management. As time goes by, the impact of the use of IS / IT has not been implemented yet, it is evidenced by the number of project works that experience delays within a certain period of time. In this study, data were obtained from observations, interviews and analysis of company documents. This research refers to the Ward and Peppard method. The results of this study are in the form of a blueprint or description of business strategy, IS / IT management strategy and IT application to achieve corporate strategic goals.
\end{abstract}

Keywords: Business, Company, Planning, Strategic, IS (Information Systems) / IT (Information Technology)

\section{PENDAHULUAN}

Teknologi informasi merupakan sebuah tools atau alat yang dapat membantu pekerjaan manusia pada zaman sekarang ini. Hampir semua kegiatan yang dilakukan memerlukan bantuan teknologi. Pesatnya perkembangan teknologi mengharuskan perusahaan untuk memanfaatkan teknologi informasi dalam membantu perusahaan agar tetap tumbuh dan mempunyai keunggulan kompetitif (competitive advantages). Keunggulan kompetitif (competitive advantages) adalah faktor penunjang yang bisa menjadi penentu untuk meningkatnya kinerja sebuah perusahaan [1]. Perusahaan merupakan sebuah unit bisnis yang telah menjadi satu kesatuan yang dapat memberikan keuntungan dimana pada umumnya mampu mencapai efektifitas dan meningkatkan efisiensi dalam menjalankan operasional bisnisnya tanpa menurunkan kualitas pada produk yang mereka miliki [2].

PT. Prima Teknologi merupakan sebuah perusahaan vendor telekomunikasi yang menjual produk (berupa aplikasi) dan memberikan layanan jasa (maintenance produk) kepada banyak provider telekomunikasi di Indonesia, seperti (Telkomsel, 
XL, AXIS dan Indosat). PT. Prima Teknologi setiap tahunnya banyak mendapatkan proyek hasil dari pemenangan tender yang diadakan oleh provider telekomunikasi tersebut. Jadi, dalam kurun waktu satu tahun yang dimulai dari setiap awal tahun, PT. Prima Teknologi sudah mempunyai daftar proyek yang akan dikerjakan berdasarkan waktu yang sudah ditentukan dalam penyelesaian proyek.

Seiring berjalannya waktu banyak sekali ditemukan pengerjaan proyek yang mengalami keterlambatan. Keterlambatan proyek disebut sebagai tertundanya penyelesaian pekerjaan yang tidak sesuai dengan kontrak kerja secara hukum yang mengakibatkan timbulnya klaim [3]. Terdapat beberapa penyebab yang mengakibatkan pengerjaan proyek menjadi terlambat, yaitu: keterlambatan pengerjaan proyek yang disebabkan karena kelalaian dari pemilik proyek, Keterlambatan jenis ini layak untuk mendapatkan ganti rugi (compensabel delay). Keterlambatan yang disebabkan oleh kelalaian atau adanya kesalahan karena pemilik tender, jenis keterlambatan ini disebut dengan non excusable Delay dan tidak layak mendapatkan ganti rugi. Keterlambatan pengerjaan proyek yang disebabkan oleh diluar kemampuan kontrol atau kendali, jenis keterlambatan ini disebut excusable delay [4]. Keterlambatan pengerjaan proyek berasal dari 2 faktor, yaitu dari kontraktor (pemenang tender) atau owner (pemilik tender) [5].

Selama ini PT. Prima Teknologi telah mempersiapkan proyek IT (Teknologi Informas) yang akan diselesaikan dalam kurun waktu satu tahun sebelumnya. Akan tetapi untuk mendukung proses pelaksanaannya PT. Prima Teknologi belum memanfaatkan dengan optimal IS/IT pada pengerjaan proyeknya. Hal tersebut dibuktikan dengan semua laporan, progress dari pengerjaan proyek hanya terdokumentasi melalui email dan dokumen tertentu. Hal seperti ini tentu tidak hanya mempersulit perusahaan dalam dokumentasi akan tetapi juga mempersulit pekerjaan karyawan dan pimpinan perusahaan untuk mengetahui kendala dan progress pelaksanaan proyek yang telah dilakukan, sehingga dengan begitu pimpinan perusahaan dapat membuat keputusan terkait proyek yang dilaksanakan.

Dengan situasi seperti ini tentu akan mengakibatkan banyaknya proyek yang mengalami keterlambatan, yang bisa mengakibatkan kurangnya kepercayaan dari pelanggan (provider telekomunikasi), menurunnya profit perusahaan, bahkan mengakibatkan tingginya tingkat turnover karyawan sehingga mengakibatkan operasional bisnis perusahaan menjadi terganggu dan juga secara tidak langsung mengakibatkan operasional bisnis perusahaan tidak lagi selaras dengan rencana strategis bisnis perusahaan. Dimana rencana strategis bisnis perusahaan merupakan sebuah pendekatan yang dipakai oleh sebuah perusahaan dalam menentukan sebuah keputusan yang menyangkut nasib masa depan dari perusahaan [6]. Dengan demikian, dibutuhkanlah sebuah perencanaan strategis SI/TI berupa investasi jangka panjang yang mengacu kepada kerangka kerja dari Ward and Peppard. Rencana Strategis SI/TI yang diterapkan tersebut harus selaras dan berjalan bersamaan dengan strategi bisnis perusahaan [7]. 


\section{METODE}

Pada penelitian ini menggunakan pendekatan metode kualitatif, yang didasarkan pada masalah yang diperoleh dari hasil pengalamatan langsung dari kondisi lapangan. Terdapat beberapa langkah dalam menyelesaikan penelitian ini, antara lain :

Langkah yang pertama adalah melakukan identifikasi terhadap masalah yang dihadapi oleh PT. Prima Teknologi, dilakukan dengan cara observasi dan tanya jawab dengan narasumber seperti GM (General Manager) Perusahaan, Setiap Staf kepala bagian (Head of finance, IT Development, Engineering Department, and Project Management) dan semua karyawan yang berhubungan dengan pengerjaan proyek IT. Kemudian masalah yang ditemukan dilapangan akan diangkat menjadi topik penelitian untuk melakukan implementasi perencanaan strategis SI/TI pada PT. Prima Teknologi.

Langkah yang kedua adalah mengkaji penelitian terdahulu yang menjadi sumber referensi atau acuan, serta memeriksa dasar teori dari Ward and Peppard yang diterapkan pada penelitian ini. Seperti penelitian terdahulu oleh Hoga Saragih dan Sashi Raza dengan judul "Incremental and Comprehensive IT Strategic Planning at PT. XYZ " yang menghasulkan usulan untuk dapat melakukan perubahan terhadap infrastruktur jaringan agar dapat menigkatkan efektifitas dan efisiensi serta mengusulkan teknologi berupa aplikasi yang dapat meningkatkan kinerja proses bisnis sehingga menghasilkan kinerja yang kompetitif. Dimulai dengan menganalisis internal dan eksternal bisnsi dengan menggunakan metode Analisa SWOT, CSF, dan Five force Porter. Selain itu penelitian dari Robert Arasa dan Peter K.Obonyo dengan judul " The Relationship Between Strategic Planning and Firm Performance" memaparkan tentang adanya hubungan antara perencanaan strategic planning dengan kinerja perusahaan dimana pada penelitian ini memberikan kontribusi dengan menyarankan bahwa setiap langkah-langkah yang dilakukan dalam perencanaan strategis memiliki hubungan dengan kinerja perusahaan. Pada penelitian lain yang dilakukan oleh Abdisalam Isa-Salwe, Munir Ahmed, Khalid Aloufi dan Muhammad Kabir dengan judul "Strategic Information System Alignment: Alignment of IS/IT With Business Strategy " memaparkan tentang bagaimana menghubungkan strategi sistem informasi dan menyelaraskan IS/IT dengan strategi bisnis. Dengan menganalisa lingkungan internal dan eksternal bisnis yang kemudian di integrasikan secara fungsional dengan strategi bisnis. Hasil penelitian menunjukkan bahwa IS/IT bekerja sebagai enabler bagi bisnis bukan sebagai transformator.

Langkah yang ketiga melakukan pengumpulan data. Data yang dipakai didapatkan dari data primer dan data sekunder. Data primer didapatkan dengan cara observasi secara langsung pada perusahaan juga mewawancarai narasumber yang mengetahui operasional bisnis perusahaan secara menyeluruh dalam hal ini adalah pemilik, direktur dan pimpinan dari masing-masing bidang yang berkaitan dengan 
Vol. 3, No. 2, June 2021

p-ISSN: 2656-5935 http://journal-isi.org/index.php/isi

e-ISSN: 2656-4882

pengerjaan proyek. Data sekunder didapatkan dari dokumen tahun perusahaan yang berisi daftar pengerjaan proyek perusahaan dalam kurun waktu tertentu.

Langkah yang keempat adalah merancang perencanaan strategis SI/TI mengacu kepada model/framework dari Ward and Peppard yang dijadikan sebagai acuan agar apa yang diinginkan pada perencanaan strategis SI/TI dapat tercapai, terlihat pada gambar 1 berikut ini :

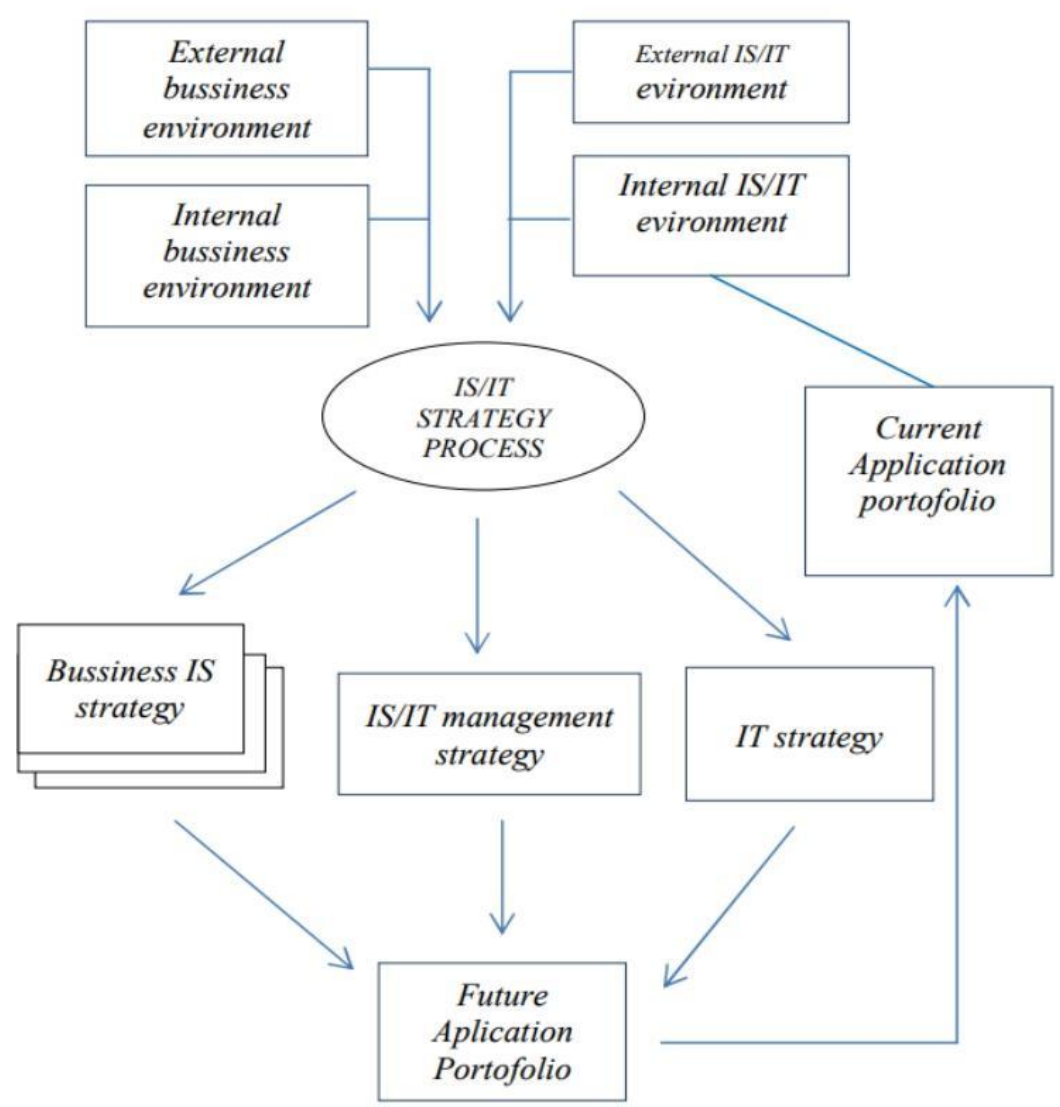

Gambar 1. Model framework perencanaan strategis SI/TI yang mengacu kepada (Ward and Peppard 2002)[8]

Terdapat beberapa metode yang dipakai pada tahapan proses analisis yaitu menggunakan analisis SWOT (Strengths, Weaknesses, Opportunities, Threats) merupakan metode yang digunakan agar dapat mengidentifikasi apa saja yang menjadi kekuatan perusahaan dengan memanfaatkan peluang dan menangani kelemahan untuk dapat bertahan terhadap ancaman yang akan datang. Metode CSF (Critical Success Factor) tidak hanya digunakan untuk mengembangkan strategi SI/TI akan tetapi juga digunakan untuk pengembangan strategi bisnis. Metode 
Vol. 3, No. 2, June 2021

p-ISSN: 2656-5935 http://journal-isi.org/index.php/isi e-ISSN: 2656-4882

Five Forces Porter digunakan untuk menganalisis persaingan sebuah industri yang bergantung kepada 5 perspektif kekuatan bersaing. Metode Strategic McFarland digunakan untuk merencanakan kontribusi yang diharapkan dari keseluruhan SI/TI untuk keberhasilan bisnis dan metode Value Chain digunakan untuk menganalisis proses bisnis / aktivitas perusahaan dengan cara menggambarkan sebuah perusahaan ke komponen kunci.

\section{HASIL DAN PEMBAHASAN}

Mengacu kepada kerangka kerja Ward and Peppard, dalam merancang perencanaan strategis SI/TI pada PT. Prima Teknologi dimulai dengan melakukan proses analisis secara mendalam pada lingkungan eksternal maupun internal dari perusahaan.

\subsection{Menganalisis Lingkungan Internal Bisnis Perusahaan}

Adapun tahapan dalam melaksanakan proses analisis terhadap lingkungan internal bisnis perusahaan yaitu dengan mengidentifikasi faktor-faktor internal apa saja yang berpengaruh terhadap proses bisnis pada PT. Prima Teknologi.

\section{Analisis SWOT}

Hasil analisis metode SWOT (Strength, Weakness, Opportunities, Threat) akan menghasilkan pemetaan berupa faktor apa saja yang menjadi kekuatan, kelemahan, peluang, dan ancaman sebuah perusahaan (PT. Prima Teknologi), yang akan dipetakan ke dalam koordinat SWOT. Dengan begitu akan terlihat berada pada kuadran mana PT. Prima Teknologi berada yang diperoleh dengan cara menghitung faktor strategi internal (IFAS) dan eksternal (EFAS) [9].

Tabel 1. Perhitungan nilai IFAS dan EFAS

\begin{tabular}{|l|l|}
\hline Titik X (Faktor strategi internal (IFAS)) & $=$ kekuatan - kelemahan \\
& $=4,5-10,4$ \\
& $=-5,9$ \\
\hline Titik Y (Faktor strategi eksternal (EFAS)) & $=$ peluang - ancaman \\
& $=5,5-3,3$ \\
& $=2,2$ \\
\hline
\end{tabular}


Vol. 3, No. 2, June 2021

p-ISSN: 2656-5935 http://journal-isi.org/index.php/isi e-ISSN: 2656-4882

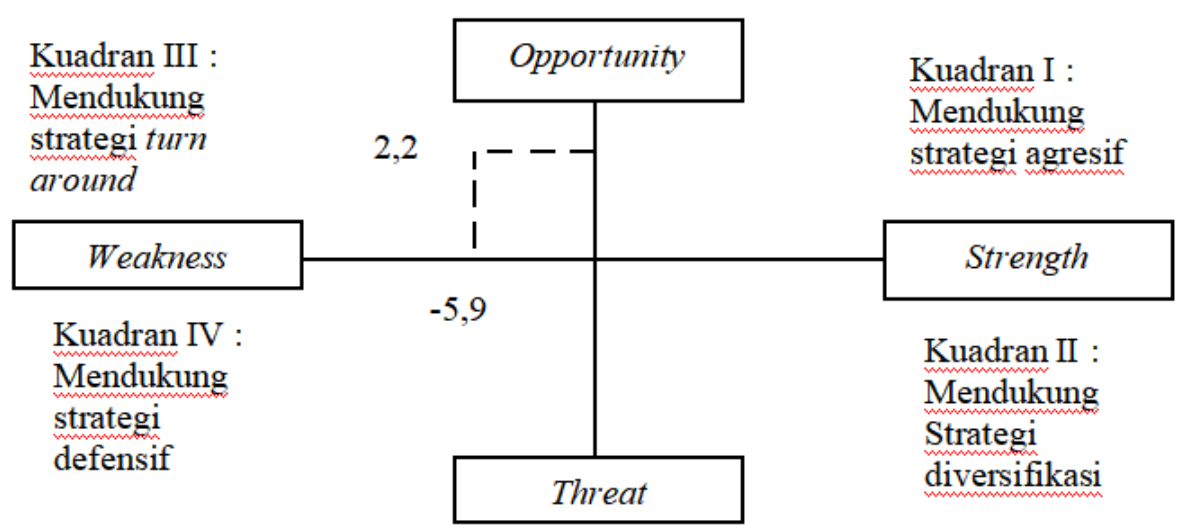

Gambar 2. Diagram analisis SWOT PT. Prima Teknologi

Pada gambar 2 terlihat bahwa PT. Prima Teknologi berada pada posisi kuadran III dengan titik koordinat $(2,2,-5,9)$. Dengan demikian PT. Prima Teknologi disarankan untuk menerapkan strategi "Turn Around". Adapun alternatif strategi yang dipakai pada strategi Weakness Opportunity (WO) adalah sebagai berikut :

Tabel 2. Strategi WO dan kebutuhan SI/TI

\begin{tabular}{|c|c|c|c|}
\hline No & Strategi WO & Usulan & Kebutuhan SI/TI \\
\hline 1 & $\begin{array}{c}\text { Perkembangan pesat } \\
\text { teknologi informasi akan } \\
\text { membantu meningkatkan } \\
\text { infrastruktur perusahaan } \\
\text { menjadi lebih baik } \\
\end{array}$ & \begin{tabular}{|} 
PT. Prima Teknologi perlu \\
meningkatkan \\
infrastruktur jaringan \\
terutama pada penggunaan \\
bandwidth
\end{tabular} & $\begin{array}{c}\text { Peningkatan bandwidth } \\
\text { jaringan agar operasional } \\
\text { bisnis perusahaan dalam } \\
\text { kegiatan pengerjaan } \\
\text { proyek tidak terganggu }\end{array}$ \\
\hline 2 & \begin{tabular}{|c|} 
Tingginya turn over \\
karyawan yang \\
menyebabkan \\
terhambatnya proses \\
transfer ilmu antara \\
karyawan lama dengan \\
karyawan baru yang bisa \\
diatasi dengan membangun \\
sistem sharing knowledge \\
management \\
\end{tabular} & \begin{tabular}{|c|} 
PT. Prima Teknologi perlu \\
membangun sebuah sistem \\
sharing knowledge management \\
sebagai wadah atau tempat \\
untuk menyimpan ilmu \\
yang diperoleh setiap \\
karyawan selama bekerja \\
pada perusahaan
\end{tabular} & $\begin{array}{c}\text { Aplikasi sharing knowledge } \\
\text { management }\end{array}$ \\
\hline 3 & $\begin{array}{c}\text { Meningkatkan kualitas } \\
\text { karyawan atau Sumber } \\
\text { Daya Manusia (SDM) } \\
\text { dengan memperbanyak } \\
\text { melakukan pelatihan atau } \\
\text { pengambilan sertifikasi } \\
\text { sesuai bidang yang didalami } \\
\text { karyawan }\end{array}$ & \begin{tabular}{|} 
PT. Prima Teknologi perlu \\
meningkatkan sumber \\
daya manusianya dengan \\
pengambilan sertifikat \\
keahlian sesuai dengan \\
bidang masing-masing
\end{tabular} & $\begin{array}{c}\text { Pelatihan / sertifikasi } \\
\text { berdasarkan bidang atau } \\
\text { proyek yang dikerjakan }\end{array}$ \\
\hline
\end{tabular}


Vol. 3, No. 2, June 2021

p-ISSN: 2656-5935 http://journal-isi.org/index.php/isi e-ISSN: 2656-4882

\section{Analisis Value Chain}

"Analisis rantai nilai adalah Strategi yang digunakan untuk memahami keunggulan kompetitif dengan mengidentifikasi seluruh aktivitas perusahaan agar dapat menurunkan biaya dan untuk memahami hubungan perusahaan dengan pemasok dan pelanggan dalam dunia industri dengan lebih baik" [10].

Pada PT. Prima Teknologi, analisa Value Chain mengacu kepada analisis proses bisnis /aktivitas bisnis dengan cara menggambarkan industri sebagai jaringan komponen kunci.

Berikut ini adalah hasil dari analisis Value Chain pada PT. Prima Teknologi terlihat pada 2 aktivitas penting yang terjadi pada perusahaan, yaitu :

A. Primary Activities (Aktifitas Utama)

1) Inbound Logistik (Logistik Masuk)

Pada aktifitas ini PT. Prima Teknologi akan saling menerima PO (Purchase Order) dari customer (operator telekomunikasi). PO ini akan dijadikan sebagai bukti bahwa customer menggunakan jasa dari PT. Prima Teknologi. Data PO beserta data pelanggan akan di inputkan kedalam aplikasi accurate.

2) Operasional

Pada aktifitas ini, PT. Prima Teknologi akan mengeksekusi proyek yang diperoleh dari customer. Proses eksekusi dimulai dari kegiatan instalasi, customer driven dan proses pengujian. Untuk saat ini belum ada sebuah sistem atau aplikasi yang dibangun untuk menunjang aktifitas ini.

3) Outbound Logistik (Logistik Keluar)

Pada aktifitas ini akan dilakukan proses UAT (User Acceptance Test) ketika proyek sudah selesai dilakukan. Proses UAT dilakukan antara engineer dengan customer untuk mengetahui kepuasan pelanggan terhadap aplikasi/proyek yang sudah dikerjakan. Apabila hasil pengujian sesuai yang diharapkan pelanggan, selanjtnya dilakukan proses BAST (Berita Acara Serah Terima) dan GR (Good Receipt) yang merupakan proses penerimaan proyek kepada customer.

4) Marketing \& Sales

Pada aktifitas ini customer sudah bisa menggunakan produk (aplikasi) yang dikerjakan oleh PT. Prima Teknologi. Setelah itu produk (aplikasi) yang sudah dikerjakan, informasinya akan dimasukkan kedalam website perusahaan sebagai upaya untuk memasarkan dan pengenalan portfolio perusahaan.

5) Pelayanan (Service)

Pada aktifitas ini, PT. Prima Teknologi memberikan pelayanan maintenance terhadap proyek atau jasa yang sudah diberikan dengan memberikan pelayanan 7x24 jam dalam 1 minggu. Untuk mendukung aktiftas ini PT. 
Vol. 3, No. 2, June 2021

p-ISSN: 2656-5935 http://journal-isi.org/index.php/isi e-ISSN: 2656-4882

Prima Teknologi tidak memiliki sebuah sistem informasi yang dapat digunakan secara otomatis dalam upaya peningkatan service kepada customer.

B. Support Activities (Aktivitas Pendukung)

1) Infrastruktur (Infrastructure)

Pada aktivitas ini, melibatkan struktur organisasi perusahaan mulai dari manajemen organisasi perusahaan, operasional keuangan, perkiraan biaya dan Gedung.

2) Human Resources Management

Pada aktifitas ini, untuk meningkatkan kualitas terhadap sumber daya manusia pada PT. Prima Teknologi mulai dari memberikan pelatihan atau sertifikasi keahlian dan peningkatan intensif karyawan.

3) Product dan technology development

Pada aktifitas ini, untuk meningkatkan infrastruktur atau produk dan jasa yang ditawarkan kepada pelanggan serta membangun sistem untuk mendukung aktivitas bisnis

4) Pengadaan (Procurement)

Pada aktiftas ini, untuk mendukung aktivitas utama meliputi pengadaan peralatan untuk mendukung pengerjaan proyek.

\subsection{Menganalisis Lingkungan Eksternal Bisnis}

Salah satu metode yang digunakan untuk menganalisis lingkungan eksternal bisnis perusahaan adalah menggunakan metode analisa Five Forces Porter yang tertuang pada 5 kekuatan bersaing porter, yaitu :

1) Pendatang Baru

Perusahaan vendor yang bergerak dibidang yang sama (telekomunikasi) yang menawarkan produk (aplikasi) dan jasa (maintenance produk) yang sama dengan PT. Prima Teknologi.

2) Produk Pengganti

Produk yang ditawarkan PT. Prima Teknologi adalah USSD atau UMB kepada pelanggan. Ancamannya adalah perubahan atau modifikasi fitur yang lebih canggih yang ditawarkan pada aplikasi USSD atau UMB oleh perusahaan lain, sehingga pelayanan lebih meningkat

3) Pesaing

Perusahaan yang sudah lebih dulu bergerak dibidang telekomunikasi yang menawarkan produk dan jasa dengan teknologi yang lebih canggih.

4) Kekuatan Pembeli

Semua provider telekomunikasi (Indosat, XL, Axis, Telkomsel) yang membutuhkan produk tersebut.

5) Kekuatan Pemasok

Partner yang saat ini selalu mendukung pegembangan terhadap produk USSD dan UMB dan membantu dalam melakukan maintenance terhadap produk. 
Vol. 3, No. 2, June 2021

p-ISSN: 2656-5935 http://journal-isi.org/index.php/isi e-ISSN: 2656-4882

\subsection{Menganalisis Lingkungan Internal SI/TI Saat Ini}

Analisis dilakukan dengan cara melihat portofolio penggunaan aplikasi saat ini pada PT. Prima Teknologi dengan menggunak metode analisis Strategic MCFarland. Dengan begitu kita akan mengetahui bagaimana kontribusi yang diharapkan dari keseluruhan SI/TI untuk keberhasilan bisnis.

1. Portofolio aplikasi saat ini

Pada portofolio aplikasi ini akan ditampilkan keseluruhan penggunaan aplikasi perusahaan yang dimasukkan kedalam empat kategori yaitu strategic, key operational, support dan high potential. Berikut ini adalah pengelompokkan kategori aplikasi pada PT. Prima Teknologi :

Tabe1 3. Kategori Portofolio Aplikasi

\begin{tabular}{|c|c|}
\hline Strategic & High Potential \\
\hline Microsoft Office & Accurate \\
& Web CMS \\
& Web reporting LBS \\
& Web reporting Pop Game \\
& Web reporting Siaranku \\
\hline Key Operational & Support \\
\hline & Website PT. Prima Teknologi \\
\hline
\end{tabular}

2. Infrastruktur jaringan saat ini

Berikut ini adalah infrastruktur jaringan pada PT. Prima Teknologi dilihat dari sisi topologi jaringan. Topologi dibawah ini adalah topologi jaringan internal PT. Prima Teknologi, didalamnya tidak termasuk topologi pelanggan perusahaan.

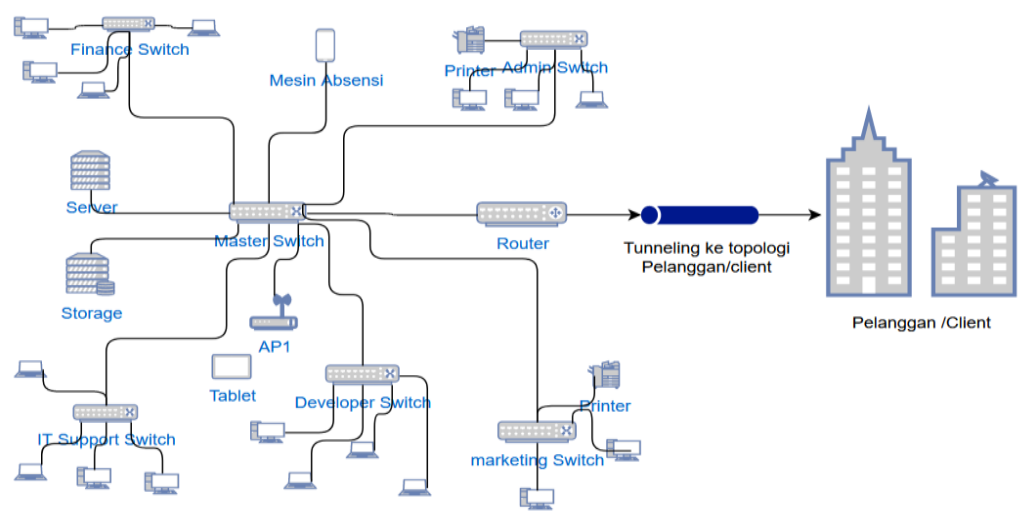

Gambar 3. Infrastruktur Jaringan PT. Prima Teknologi Saat Ini 
Vol. 3, No. 2, June 2021

p-ISSN: 2656-5935 http://journal-isi.org/index.php/isi e-ISSN: 2656-4882

\subsection{Menganalisis Lingkungan Eksternal SI/TI}

Proses analisis lingkungan eksternal SI/TI dilakukan dengan melihat dan meninjau perkembangan teknologi saat ini dan juga terhadap pesaing bisnis yang membantu perkembangan bisnis yang bergerak di bidang yang sama (telekomunikasi) yang sama dengan PT. Prima Teknologi.

\subsection{Future Bisnis}

\section{Strategi Bisnis SI}

Pada Perencanaan strategi Sistem Informasi (SI) bertujuan untuk memperoleh solusi bagaimana fungsi bisnis menyebarkan SI/TI di perusahaan untuk mencapai tujuan perusahaan. Berikut usulan strategi bisnis sistem informasi (SI) untuk mendukung operasional bisnis perusahaan dalam mencapai visi misi nya:
a. Aplikasi Sharing Knowledge Management
b. Aplikasi Project Management
c. Aplikasi Maintenance Project

\section{Strategi Manajemen SI/TI PT. Prima Teknologi}

Dengan menindaklanjuti usulan perencanaan strategi SI/TI maka pada sisi manajemen perlu ditambahkan sebuah divisi baru yaitu research and development (RnD) yang bertugas untuk mengembangkan produk atau aplikasi yang ditawarkan oleh PT. Prima Teknologi kepada pelanggannya (provider telekomunikasi) bahkan bisa membangun sendiri aplikasi yang dibutuhkan pelanggan dengan memanfaatkan Sumber Daya Manusia (SDM) dari PT. Prima Teknologi tanpa harus bergantung kepada partner sehingga kebutuhan pasar dan tuntutan pelanggan dapat terpenuhi.

Berikut ini merupakan usulan kebutuhan Sumber Daya Manusia (SDM) pada manajemen SI/TI pada PT. Prima Teknologi :

Tabel 4. Usulan sumber daya manusia

\begin{tabular}{|c|c|c|}
\hline No & Sumber Daya Manusia & Jumlah \\
\hline 1 & Team Leader & 1 \\
\hline 2 & Senior Consultant & 2 \\
\hline 3 & Engineer & 5 \\
\hline
\end{tabular}

\section{Strategi TI}

Pada tahapan ini, menghasilkan rekomendasi kebutuhan TI untuk masa depan perusahaan, dimulai dari : 
Vol. 3, No. 2, June 2021

p-ISSN: 2656-5935 http://journal-isi.org/index.php/isi e-ISSN: 2656-4882

\section{a. Usulan Hardware}

Sebenarnya untuk saat ini hardware yang digunakan pada PT. Prima Teknologi sudah cukup memenuhi kebutuhan untuk pelaksanaan operasional bisnis, berikut kebutuhan hardware pada PT. Prima Teknologi :

Tabel 5. Usulan hardware

\begin{tabular}{|c|c|c|}
\hline No & Nama Perangkat & Jumlah \\
\hline 1 & Router & 1 \\
\hline 2 & Switch & 6 \\
\hline 3 & Server & 4 \\
\hline 4 & PC/Desktop & 3 \\
\hline 5 & Laptop & 70 \\
\hline 6 & Printer & 4 \\
\hline
\end{tabular}

b. Usulan Software

Terdapat beberapa pembaharuan update terhadap software yang digunakan saat ini, untuk kebutuhan pengembangan SI/TI, Adapun software tersebut antara lain:

Tabel 6. Usulan Hardware

\begin{tabular}{|c|l|l|}
\hline Jenis & Nama Software & Usulan \\
\hline Software & Redhat Linux 7 & upgrade \\
\hline
\end{tabular}

c. Usulan Infrastruktur Jaringan

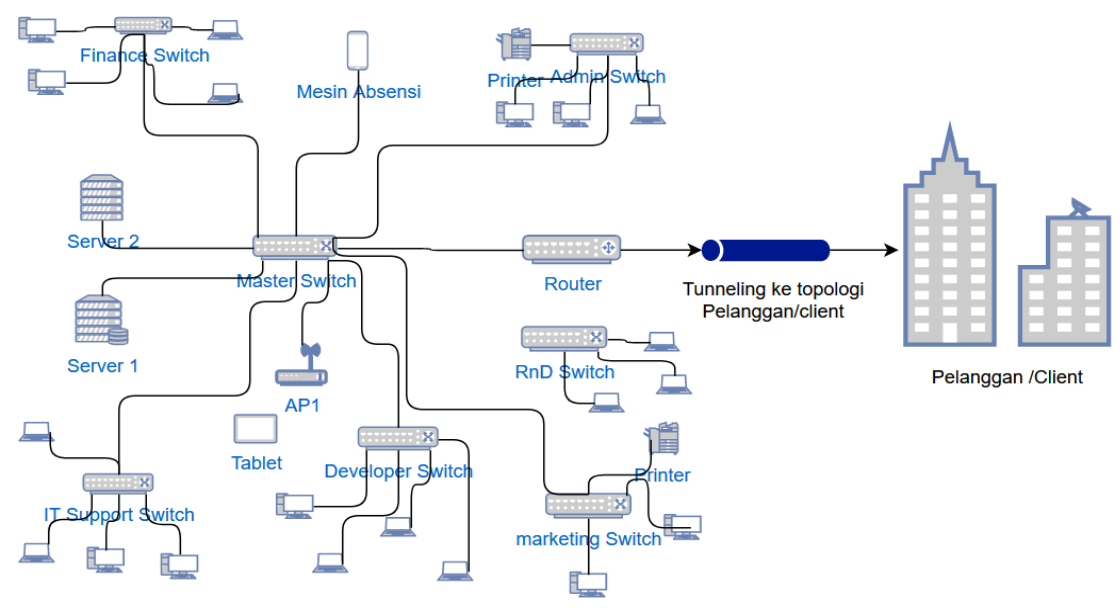

Gambar 4. Usulan Infrastruktur Jaringan PT. Prima Teknologi

\subsection{Portofolio Aplikasi Masa Depan}

Berikut ini adalah pemetaan terhadap matriks portofolio aplikasi keseluruhan pada PT. Prima Teknologi menggunakan metode Strategic MCFarland : 
Vol. 3, No. 2, June 2021

p-ISSN: 2656-5935 http://journal-isi.org/index.php/isi e-ISSN: 2656-4882

Tabel 7. Usulan Portofolio Aplikasi PT. Prima Teknologi

\begin{tabular}{|c|cc|}
\hline Strategic & High Potential \\
\hline - Sharing Knowledge Management & - & Accurate (telah ada) \\
(aplikeasi baru) & - & Web CMS (telah ada) \\
& - & Web reporting LBS (telah ada) \\
& & Web reporting Pop Game (telah \\
& ada) \\
& - & Web reporting Siaranku (telah ada) \\
& & Support \\
\hline$-\quad$ Maintenance Project (aplikeasi baru) & Website PT. Prima Teknologi (telah ada) \\
\hline
\end{tabular}

\section{KESIMPULAN}

Berikut ini adalah kesimpulan yang diperoleh dari hasil penelitian yang telah dilakukan adalah PT. Prima Teknologi harus membangun sebuah sistem berbasis teknologi seperti :

a. Sharing knowledge management untuk meningkatkan dan memelihara pengetahuan karyawan agar dapat dimanfaatkan karyawan baru dalam pengerjaan project.

b. Project management untuk mempermudah karyawan dalam melaporkan hasil pengerjaan proyek secara realtime terkait kendala yang dihadapi sewaktu pengerjaan proyek dan mempermudah manajemen dalam pengambilan keputusan

c. Maintenance project untuk meningkatkan kualitas layanan jasa terhadap keluhan pelanggan

d. Meningkatkan bandwidth jaringan untuk mempermudah operasional bisnis perusahaan

e. Membangun divisi Research and Development $(\mathrm{RnD})$ yang mampu membuat dan mengembangkan produk (aplikasi) dan jasa yang ditawarkan ke pelanggan.

\section{DAFTAR PUSTAKA}

[1] Supriyanto, "Pemberdayaan Teknologi Informasi Untuk Keunggulan Bisnis," J. Ekon. Pendidik., vol. 2, no. 1, pp. 99-112, 2004.

[2] Farlianto, "STUDI FAKTOR-FAKTOR KETERLAMBATAN PROYEK PADA KONTRAKTOR DI DAERAH ISTIMEWA YOGYAKARTA,” J. Ilmu Manaj., vol. 12, no. 2, pp. 10-27, 2015.

[3] A. Bakhtiyar, A. Soehardjono, and M. H. Hasyim, "Analisis Faktor-Faktor Yang Mempengaruhi Keterlambatan Proyek Konstruksi Pembangunan Gedung Di Kota Lamongan," J. Rekayasa Sipil, vol. 6, no. 1, pp. 55-66, 2012. 
[4] Z. M. Kraiem and J. E. Diekmann, "Concurrent Delays in Construction Projects," J. Constr. Eng. Manag., vol. 113, no. 4, pp. 591-602, 1987.

[5] F. Kamaruzzaman, "Studi Keterlambatan Penyelesaian Proyek Konstruksi (Study of Delay In The Completion Of Construction Projects)," J. TEK. SIPIL UNTAN, vol. 12, no. 2, pp. 175-190, 2012.

[6] A. Y. Hamali, "Pemahaman Strategi Bisnis dan Kewirausahaan," Jakarta Prenadamedia Gr., 2016.

[7] A. S. Nugroho, W. W. Winarno, and H. A. Fatta, "Strategic Information Systems Planning And Information Technology For School," Widyagogik J. Pendidik. dan Pembelajaran Sekol. Dasar, vol. 8, no. 1, pp. 1-7, 2020.

[8] J. Peppard and J. Ward, Strategic planning for information systems, vol. 2, no. 3. John Wiley \& Sons Incorporated, 2003.

[9] N. P. Sriminangga and F. Samopa, "Strategic Planning of Information Systems/Information Technology at KOMINFO Department in Malang," Int.J. Educ. Res., vol. 5, no. 1, 2017.

[10] J. Marissa, R. Syahni, R. A. Hadiguna, and Novialdi, "Analisis Strategi Rantai Nilai (Value Chain) Untuk Keunggulan Kompetitif Melalui Pendekatan Manajemen Biaya Pada Industri Pengolahan Ikan," J. Anim. Sci. Agron. Panca Budi, vol. 2, no. 02, pp. 7-17, 2017, [Online]. Available: http://jurnal.pancabudi.ac.id/index.php/jasapadi/article/view/97.

[11] H. Saragih and S. Raz (2013), "Incremental and Comprehensive IT Strategic Planning at PT. XYZ", International Journal of Information Technology and Business Management Vol. 17 No.1

[12] A. J. G. Silvius and J. Stoop (2013), “ The Relationship Between Strategic Information Systems Planning Situational Factors, Process Configuration and Success ", International Information Management Association

[13] A. Issa-Salwe, M. Ahmed, K. Aloufi and M. Kabir (2010), "Strategic Information Systems Alignment: Alignment of IS/IT With Business Strategy, Journal of Information Processing Systems. 